\title{
CONDOM USE BY NEPALESE YOUTH AT LAST SEX WITH MOST RECENT PARTNER OTHER THAN WIFE OR NON-LIVE-IN PARTNER
}

\author{
Dhanendra Veer Shakya*
}

This study attempts to examine the effects of some selected socio-economic variables like level of education, occupation, current working status, wealth index, place of residence and frequency of exposure to mass media like newspapers/magazines, radio and television; demographic variables like age group, age at first sex, marital status, migration status and travelling away from home in the past 12 months; and cultural variables like religion and caste/ethnicity, and spatial distribution by ecological zones, development regions and provinces on condom use by Nepalese youth males at last sex with most recent partner other than wife or non-live-in partner using multivariate logistic regression analysis. It has used 2016 Nepal Demographic and Health Survey data files with weighted cases. Data are analyzed using percentage and frequency tables and statistical tests are carried out using binomial logistic regression analysis of dependent variable controlling for the independent variables presented in the table of this study.

The significant findings of the study are that youth males with primary level of education are less likely to use condom at last sex with most recent partner other than wife or nonlive-in partner than those who have higher than secondary level of education. Not working youth males are more likely to use condom than those engaged agricultural occupation. Likewise, ever married youth males are less likely to use condom than their never married counterparts. Newar youth males are less likely to use condom than youth males of Hill Chhetri. Youth males living in Terai are less likely to use condom than youth males living in Hill. Similarly, youth males living in Far-western region are more likely to use condom compared to their counterparts of Central regions.

Keywords: Youth males, last sex, most recent partner other than wife, non-live-in-partner, condom useand odds ratio.

\section{BACKGROUND}

Studies have indicated the link between the relationship type and condom use at last sex. Youth and adults who have most recent intercourse outside a relationship use condom more than those who have intercourse within a relationship. For those within ongoing relationships, pregnancy prevention is of great importance. In contrast, for those whose last sexual encounter occurred outside of an ongoing relationship, disease prevention is the most important (Anderson, Wilson, Doll, Jones, \& Barker, 1999). A U.S. national survey had shown that condom use at last intercourse outside of ongoing relationships was higher among males, the more highly educated, those living in large metropolitan areas and those with two or more partners.

Condom use at last sex found varied by partner types among married/cohabiting and unmarried/non-cohabiting. Among men condom use was somewhat higher with a partner that they paid for sex. Among married men or men in a cohabiting relationship, only 7 percent used a condom with their wife or cohabiting partner at last sex. In contrast, over 38 percent used a

* Dr. Shakya is Associate Professor at Central Department of Population Studies (CDPS), Tribhuvan University, Kirtipur, Kathmandu, Nepal. 
condom with their regular partner, and 31 percent with an acquaintance. Condom use was higher, however, among both men and women who practiced higher risk sexual behaviours. For example, men with more than one sexual partner were about three times as likely to have used a condom at last sex as those with only one partner. Condom use at last sex was twice as high among those who reported having an STI in the past 12 months (Waithaka \& Bessinger, 2001).

If husband had other partners, wife had a higher risk of STIs if husbands did not use a condom the last time they had sex with partners other than their wives. The low frequency of condom use within marriage and the high frequency of extramarital sex among men suggest that a substantial proportion of married people will be exposed to STIs through unprotected sexual intercourse with their STI-infected spouse (Amornkul et al., 2009). There is a significant relationship between number of partners and condom use during last sexual episode. Persons having sex with multiple partners are much less likely to have used a condom during their last sexual episode compared to those who do not have multiple partners (Nnedu, McCorvey, Campbell-Forrester, Chang, Salihu, \& Jolly, 2008).

Sexually transmitted infections (STIs), including HIV/AIDS are major health consequences associated with unprotected sexual activity. Condoms, if used correctly, can greatly reduce, though not eliminate, the risk of STIs. Although the majority of adolescents believe that sex without a condom is not worth the risk, many teens are misinformed about the protection that condoms provide against STIs and HIV/AIDS (Child Trends, 2010).

Comparing the two most recent DHS surveys in each of five sub-Saharan countries Burkina Faso, Cameroon, Kenya, Tanzania, and Zambia, multivariate analysis showed that higher education was a consistently strong, positive predictor of condom use at last higher-risk sex, whereas higher wealth status was not significant in most surveys. Knowledge that use of condoms can reduce the risk of HIV transmission is a consistently strong, positive predictor of condom use, but urban-rural residence and regions had significant differences in condom use during the last sex in some surveys (Adair, 2008).

One Kenyan survey which incorporated intensive information about condom use at last sex in the context of HIV prevention had shown that condom use varied significantly by the sociodemographic characteristics among both men and women. Men were more likely to have used a condom if they were in the 20-24 years age group. Condom use increased with higher levels of educational attainments. With respect to marital status, condom use at last sex most frequently occurred among unmarried than those who were married. Long-term urban residents and recent migrants were also more likely to use a condom than long-term rural residents (Waithaka \& Bessinger, 2001). The association also exists between exposure to AIDS information in the mass media and condom use. Men who heard about AIDS on the radio, on television, or read about AIDS in the newspaper, were about twice likely to use a condom than those who were not exposed.

A study of condom use at last sex among adolescents in the four districts in Tanzania indicated that 61 percent did not use condoms at the last sexual intercourse and about 42 percent of them had sex with multiple partners in the last 12 months. More than three-fifths of those reporting multiple partners did not use condoms at their last sexual intercourse. The likelihood of condom use was 
higher among older adolescents (15-19) compared to the younger ones (10-14), possibly due to knowledge differentials about transmission and prevention of STIs (Exavery et al., 2011).

The surveys conducted during 2000-2006 in different parts of the world had shown that percentage of young people who used condom at last high-risk sex (with non-cohabiting and non-marital sexual partner) was 37 percent among males and 22 percent among females in India. It was 68 percent among Vietnamese young males (UNICEF, 2007). The highest percentages were observed in Botswana (88\% males and $75 \%$ females), whereas the lowest was found in Madagascar $(12 \%$ males and $5 \%$ females).

The calculations from NDHS data show that there is drastic change in proportion of youth males having most recent sex partner was other than wife or non-live-in-partner over time. It was only 17 percent in 2006, which increased to about 35 percent in 2011 and further increased to around 40 percent in 2016, an increase by almost 23 percentage points over 10 years period (Shakya, 2018,p. 192). It reveals that incidence of sexual relation of youth males before marriage and outside marital union is in increasing trend. Statistical test also indicates that youth males in 2016 and 2011 were more likely to have most recent sex partner other than wife or non-live-in-partner compared to that in 2006 with odds ratios of $3.142(\mathrm{p}<0.001)$ and $2.550(\mathrm{p}<0.001)$ respectively. Use or non-use of condom during sex with non-regular partner is an important indicator to measure extent of risky sexual behaviour of any person. The calculations from NDHS data show that the proportion of youth males using condom at last sex, if last sex partner was other than wife or non-live-in-partner, declined from 77 percent in 2006 to 73 percent in 2011 and 69 percent in 2016 (Shakya, 2018, p.193). The declining trend of condom use at last sex with non-regular partner can make youth males at more risk of contracting STIs.

\section{DATA AND METHODS}

This study has used the data files of 2016 Nepal Demographic and Health Surveys to examine the effects of some selected socio-economic variables like level of education, occupation, current working status, wealth index, place of residence and frequency of exposure to mass media like newspapers/ magazines, radio and television; demographic variables like age group, age at first sex, marital status, migration status and travelling away from home in the past 12 months; and cultural variables like religion and caste/ethnicity, and spatial distribution by ecological zones, development regions and provinces on condom use by Nepalese youth (15-24 years) at last sex with most recent partner other than wife or non-live-in partner.

The weighted data are used from the survey data files for the purpose of analysis. The weighted sample size of youth males was 1,580 . Similarly, the weighted sample size of youth males who have ever had sexual experience was 666 and weighted cases of youth males who reported that they had most recent sex partner other than wife or non-live-in partner was only 224.

Data are analyzed using percentage and frequency tables and statistical tests are carried out using logistic regression analysis with binomial dependent variable of condom use at last sex with most recent partner other than wife or non-live-in partner controlling for independent variables presented in the table of this study. The statistical tests are carried out using multivariate logistic regression and outcomes are interpreted with the help of indicators like odds ratio, model chisquare, two different coefficients of determination Cox and Snell $\mathrm{R}^{2}$ and Nagelkerke $\mathrm{R}^{2}$, and 
Hosmer and Lemeshow's chi-square goodness of fit along with levels of significance and 95 percent confidence interval (CI).

\section{RESULTS}

\section{Most recent sex partner other than wife or non-live-in partner and use of condom}

Considering the number of cases, regular and non-regular last (most recent) sex partner of youth males are categorized in this study into two categories viz. regular partneras wife or live-in-partner and non-regular partner as other than wife or non-live-in-partner for the purpose of the study.Nearly 40 percent Nepalese youth males had most recent sex partner other than wife or nonlive-in partner in 2016 and out of them about 69 percent had used condom at last sexual intercourse withmost recent sex partner other than wife or non-live-in partner. It means almost one-third of them did not use condom at last sex with most recent partner other than wife or nonlive-in partner. This may indicate their risky sexual behaviour and can put them at verge of vulnerability in contracting STIs including HIV/AIDS.

\section{Education}

The proportion of youth males using condom at last sex with most recent partner other than wife or non-live-in partner has increased with increase in level of education, except for primary level of education.It was 67 percent for those who had no education, 39 percent for primary level of education, 70 percent for secondary level of education and 75 percentfor higher level of education (Table 1).

When data on condom use at last sex with most recent partner other than wife or non-live-in partner were analyzed using multivariate regression analysis, it is found that youth males having primary level of education are 0.202 times less likely (with $95 \% \mathrm{CI}$ of $0.047-0.872$ ) to use condom at last sex with most recent partner other than wife or non-live-in partner than those who have higher than secondary level of education, the data is also statistically significant at $\mathrm{p}<0.05$ level.

Both youth males with no education and secondary level of education are also less like to use condom at last sex with most recent partner other than wife or non-live-in partner than those who have higher than secondary level of education. The values of odds ratios for the former two are 0.559 and 0.943 respectively, i.e. the former two are less likely by these times than the latter.However, the values of odds ratios are not found statistically significant at $\mathrm{p} \leq 0.05$ level.

\section{Occupation, working status and wealth index}

More youth males categorized with occupation of not working comprised higher proportion (79\%) in using condom at last sex with most recent partner other wife or non-live-in partner compared to others involved in manual work (68\%), agriculture (63\%) and non-agriculture $(58 \%)$ occupations. It shows that more youth males engaged in non-agriculture occupation than in other types had not used condom at last sex with most recent partner other than wife or non-live-in partner.

The multivariate regression analysis showed that not working youth males are 4.026 times more likely (with $95 \% \mathrm{CI}$ of $1.295-12.515$ ) to use condom at last sex with most recent partner other than wife or non-live-in partner than those whose occupation is agriculture and the data is also statistically significant at $p<0.05$ level. It is also found that youth males whose occupation is manual work are also more likely $(\mathrm{OR}=1.305)$, but those who are engaged in non-agriculture are 
less likely $(\mathrm{OR}=0.791)$ to use condom at last sex with most recent partner other than wife or nonlive-in partner than those whose occupation is agriculture. However, the odds ratios of both manual workers and those engaged in non-agriculture are not found statistically significant at $\mathrm{p} \leq 0.05$ level.

There was not much variation according to current working status of youth males as slightly more than 69 percent and 68 percent of those who were currently not working and working at the time of enumeration respectively had used condom at last sex with most recent partner other than wife or non-live-in partner. Data analysis reveal that currently working youth males are 2.256 times more likely to use condom at last sex with most recent partner other than wife or non-live-in partner than those who are currently not working, but the odds ratio is notfound statistically significant at $\mathrm{p} \leq 0.05$ level.

Table 1: Distribution of youth male respondents using condom at last sex with partner other than wife or non-live-in partner and effects of selected socio-economic, demographic, and cultural variables and spatial distribution on it (using logistic regression), 2016

\begin{tabular}{|c|c|c|c|}
\hline \multirow[t]{2}{*}{ Variables } & \multicolumn{2}{|c|}{ Respondents } & \multirow[b]{2}{*}{ Odds ratio $(95 \% \mathrm{CI})$} \\
\hline & Percent & Total (n) & \\
\hline \multicolumn{4}{|l|}{ Socio-economic variables } \\
\hline \multicolumn{4}{|l|}{ Educational level } \\
\hline No education & 66.7 & 12 & $0.559(0.097-3.217)$ \\
\hline Primary & 38.9 & 18 & $0.202 *(0.047-0.872)$ \\
\hline Secondary & 70.3 & 128 & $0.943(0.375-2.372)$ \\
\hline Higher & 75.4 & 65 & Ref. \\
\hline \multicolumn{4}{|l|}{ Occupation } \\
\hline Agriculture & 63.3 & 49 & Ref. \\
\hline Not working & 79.1 & 67 & $4.026 *(1.295-12.515)$ \\
\hline Manual work & 68.3 & 60 & $1.305(0.495-3.441)$ \\
\hline Non-agriculture & 57.8 & 45 & $0.791(0.274-2.289)$ \\
\hline Other/don't know & 100.0 & 2 & - \\
\hline \multicolumn{4}{|l|}{ Current working status } \\
\hline No & 69.5 & 95 & Ref. \\
\hline Yes & 68.0 & 128 & $2.256(0.816-6.239)$ \\
\hline \multicolumn{4}{|l|}{ Wealth status } \\
\hline Poorest & 72.7 & 33 & $0.676(0.172-2.666)$ \\
\hline Poorer & 59.4 & 32 & $0.535(0.150-1.914)$ \\
\hline Middle & 78.2 & 55 & $1.092(0.354-3.375)$ \\
\hline Richer & 57.4 & 54 & $0.502(0.173-1.452)$ \\
\hline Richest & 72.0 & 50 & Ref. \\
\hline \multicolumn{4}{|l|}{ Place of residence } \\
\hline Rural & 74.4 & 78 & Ref. \\
\hline Urban & 65.8 & 146 & $0.585(0.269-1.270)$ \\
\hline \multicolumn{4}{|c|}{ Reading newspaper/magazine } \\
\hline Not at all & 63.8 & 94 & $0.929(0.329-2.627)$ \\
\hline Less than once a week & 77.9 & 77 & $1.248(0.490-3.182)$ \\
\hline At least once a week & 62.3 & 53 & Ref. \\
\hline \multicolumn{4}{|l|}{ Listening to radio } \\
\hline Not at all & 57.1 & 63 & $0.676(0.291-1.570)$ \\
\hline Less than once a week & 78.8 & 80 & $1.647(0.723-3.755)$ \\
\hline
\end{tabular}


Table 1: continued

\begin{tabular}{|c|c|c|c|}
\hline \multirow[t]{2}{*}{ Variables } & \multicolumn{2}{|c|}{ Respondents } & \multirow[b]{2}{*}{ Odds ratio $(95 \% \mathrm{CI})$} \\
\hline & Percent & Total (n) & \\
\hline At least once a week & 67.5 & 80 & Ref. \\
\hline Watching television & & & \\
\hline Not at all & 67.6 & 34 & $1.075(0.391-2.955)$ \\
\hline Less than once a week & 72.7 & 66 & $1.118(0.494-2.530)$ \\
\hline At least once a week & 66.7 & 123 & Ref. \\
\hline \multicolumn{4}{|c|}{$\begin{array}{l}\mathrm{n}=224, \text { model } \chi^{2}=36.319^{* *}, \quad-2 \mathrm{LL} \quad \mathrm{BM}=278.649, \quad-2 \mathrm{LL}=242.330, \quad \mathrm{R}_{\mathrm{CS}}^{2}=0.150 \quad \& \mathrm{R}_{\mathrm{N}}^{2}=0.210, \quad \mathrm{H} \quad \& \quad \mathrm{~L}^{\prime} \mathrm{s} \\
\chi^{2}=20.680^{* *}\end{array}$} \\
\hline \multicolumn{4}{|l|}{ Demographic variables } \\
\hline \multicolumn{4}{|l|}{ Age group (in years) } \\
\hline $15-19$ & 67.5 & 117 & Ref. \\
\hline $20-24$ & 70.1 & 107 & $1.430(0.728-2.806)$ \\
\hline \multicolumn{4}{|l|}{ Age at first sexual intercourse (mean=16.8) } \\
\hline \multicolumn{4}{|l|}{ Marital status } \\
\hline Never married & 71.2 & 215 & Ref. \\
\hline Ever Married & 0.0 & 8 & $0.020 *(0.001-0.730)$ \\
\hline \multicolumn{4}{|l|}{ Migration status } \\
\hline Non-migrant & 72.6 & 168 & Ref. \\
\hline Migrant & 54.2 & 48 & $0.585(0.282-1.217)$ \\
\hline Visitor & 75.0 & 8 & $1.348(0.235-7.746)$ \\
\hline \multicolumn{4}{|l|}{ Travel away from home in last 12 months } \\
\hline No & 75.0 & 8 & $1.216(0.249-5.945)$ \\
\hline Yes & 68.5 & 216 & Ref. \\
\hline \multicolumn{4}{|c|}{$\begin{array}{l}\mathrm{n}=224, \text { model } \chi^{2}=20.491^{* *},-2 \mathrm{LL} B M=278.648,-2 \mathrm{LL}=258.157, \mathrm{R}_{\mathrm{CS}}^{2}=0.087 \& \mathrm{R}_{\mathrm{N}}^{2}=0.123, \mathrm{H} \& \mathrm{~L}^{\prime} \mathrm{s} \\
\chi^{2}=8.614\end{array}$} \\
\hline \multicolumn{4}{|l|}{ Cultural variables } \\
\hline \multicolumn{4}{|l|}{ Religion } \\
\hline Hindu & 71.4 & 185 & Ref. \\
\hline Bouddha & 47.1 & 17 & $0.553(0.130-2.357)$ \\
\hline Muslim & 68.8 & 16 & $0.672(0.119-3.797)$ \\
\hline Kirat & 50.0 & 2 & $0.404(0.018-9.026)$ \\
\hline Christian & 50.0 & 4 & $0.196(0.019-2.015)$ \\
\hline \multicolumn{4}{|l|}{ Caste/ethnicity } \\
\hline Hill Brahmin & 83.3 & 24 & $1.215(0.270-5.457)$ \\
\hline Hill Chhetri & 81.1 & 37 & Ref. \\
\hline Other Terai caste & 73.3 & 30 & $0.802(0.159-4.944)$ \\
\hline Hill Dalit & 73.3 & 15 & $0.423(0.093-1.927)$ \\
\hline Terai Dalit & 38.5 & 13 & $0.193(0.034-1.099)$ \\
\hline Newar & 43.8 & 16 & $0.228 *(0.055-0.940)$ \\
\hline Hill Janajati & 60.9 & 28 & $0.624(0.169-2.308)$ \\
\hline Terai Janajati & 74.1 & 20 & $0.696(0.156-3.094)$ \\
\hline Muslim & 68.8 & 11 & - \\
\hline Spatial distribution & & & \\
\hline Ecological zone & & & \\
\hline
\end{tabular}


Table 1: continued

\begin{tabular}{|c|c|c|c|}
\hline \multirow[t]{2}{*}{ Variables } & \multicolumn{2}{|c|}{ Respondents } & \multirow[b]{2}{*}{ Odds ratio $(95 \% \mathrm{CI})$} \\
\hline & Percent & Total (n) & \\
\hline Hill & 71.3 & 87 & Ref. \\
\hline Mountain & 68.4 & 19 & $0.635(0.157-2.565)$ \\
\hline Terai & 66.9 & 118 & $0.235 *(0.061-0.911)$ \\
\hline \multicolumn{4}{|l|}{ Region } \\
\hline Eastern & 75.9 & 29 & - \\
\hline Central & 58.2 & 79 & Ref. \\
\hline Western & 71.4 & 70 & $0.900(0.108-7.518)$ \\
\hline Mid-western & 73.3 & 30 & $0.939(0.207-2.265)$ \\
\hline Far-western & 87.5 & 16 & $8.262 *(1.197-57.006)$ \\
\hline \multicolumn{4}{|l|}{ Province } \\
\hline Province 1 & 74.1 & 27 & - \\
\hline Province 2 & 66.7 & 33 & $4.606(0.861-24.649)$ \\
\hline Province 3 & 54.2 & 48 & Ref. \\
\hline Province 4 & 77.8 & 27 & $2.100(0.230-19.176)$ \\
\hline Province 5 & 70.0 & 60 & $5.258(0.667-41.461)$ \\
\hline Province 6 & 69.2 & 13 & - \\
\hline Province 7 & 87.5 & 16 & - \\
\hline Total & 68.8 & 224 & \\
\hline \multicolumn{4}{|c|}{$\begin{array}{l}n=224, \text { model } \chi^{2}=30.987,-2 L L \quad B M=278.648,-2 L L=247.661, \quad R_{C S}^{2}=0.129 \quad \& R_{N}^{2}=0.182, H \quad \& \quad L^{\prime} s \\
\chi^{2}=7.913\end{array}$} \\
\hline
\end{tabular}

Note: The outcomes of multivariate logistic regression controlling only socio-economic, demographic, and cultural and spatial factors presented in the table separately for the corresponding variables in each section.

Source: Nepal Demographic and Health Survey, 2016 Data Files.

${ }^{*} \mathrm{p} \leq .05,{ }^{* *} \mathrm{p} \leq .01, * * * \mathrm{p} \leq .001 ;$; - ' indicating values not shown by logistic regression due to redundancies of data;

Ref.: Reference category; LL = log likelihood; LL BM = log likelihood base model;

$\mathrm{R}_{\mathrm{CS}}^{2}=$ Cox and Snell $\mathrm{R}^{2}$; and $\mathrm{R}_{\mathrm{N}}^{2}=$ Nagelkerke $\mathrm{R}^{2} ; \mathrm{H} \& \mathrm{~L}$ 's $\chi^{2}=$ Hosmer and Lemeshow's $\chi^{2}$ goodness of fit.

There is no any pattern as such in condom use at last sex with most recent partner other than wife or non-live-in partner according to wealth index as it was found that 73 percent poorest, 59 percent poorer, 78 percent middle, 57 percent richer and 72 percent richest had used condom. The figures are ups and downs as the level of wealth index increases, so it may imply that wealth status has no impact on use of condom at last sex with most recent partner other than wife or non-live-in partner. Multivariate regression analysis shows that youth males with wealth index of middle category are more likely $(\mathrm{OR}=1.092)$, but the rests of all, i.e. richer, poorer and poorest are less likely $(\mathrm{OR}=0.502, \mathrm{OR}=0.535$ and $\mathrm{OR}=0.676$ respectively) to use condom at last sex with most recent partner other than wife or non-live-in partner than those who are richest. However, none of these odds ratios are found statistically significant at $\mathrm{p} \leq 0.05$ level. 


\section{Place of residence}

Similarly, higher proportion of youth males living in rural area than in urban area (74\% vs. 66\%) had used condom at last sex with most recent partner other than wife or non-live-in partner.Multivariate regression analysis depicts that youth males living in urban areas are 0.585 times less likely to use condom at last sex with most recent partner other than wife or non-live-in partner than their counterparts living in rural areas. However, the value of odds ratio is not found statistically significant at $\mathrm{p} \leq 0.05$ level.

\section{Exposure to mass media}

Regarding to exposure to mass media, more youth males who use print media like newspapers/magazines or listened to radio or watched television less than once a week were found using condom at last sex with most recent partner other than wife or non-live-in partner than both of their counterparts who used these mass media not at all and at least once a week. The proportions of youth males using condom at last sex with most recent partner other wife or nonlive-in partner for corresponding frequency of exposures to these mass media are 78 percent versus 64 percent and 62 percent, 79 percent versus 57 percent and 68 percent, and 73 percent versus 68 percent and 67 percent respectively.

Youth males who read newspaper/magazine less than once a week are more likely $(\mathrm{OR}=1.248)$, but those who read not at all are less likely $(\mathrm{OR}=0.929)$ to use condom at last sex with most recent partner other than wife or non-live-in partner than those who read at least once a week. Similarly, those who listen to radio less than once a week are more likely $(\mathrm{OR}=1.647)$, but those who listen not at all are less likely $(\mathrm{OR}=0.676)$ to use condom at last sex with most recent partner other than wife or non-live-in partner than those who listen at least once a week. Likewise, both of those who watch television less than once a week and not at all are more likely $(\mathrm{OR}=1.118$ and $\mathrm{OR}=1.075$ respectively) to use condom at last sex with most recent partner other than wife or non-live-in partner than those who watch at least once a week. But none of these odds ratios are found statistically significant at $\mathrm{p} \leq 0.05$ level.

The significant model $\chi^{2}$ value $(\mathrm{p} \leq 0.01)$ in the table suggests that inference can be drawn from the sample for relationships between demographic variables and condom use at last sex with most recent partner other than wife or non-live-in partner. The model explained 15.0 to 21.0 percent of variance on condom use by two different $\mathrm{R}^{2}$ values. However, significant value $(\mathrm{p}<.05)$ of Hosmer and Lemeshow's $\chi^{2}$ goodness of fit suggests that predicted values in the model may differ from the observed data.

\section{Age group and age at first sex}

Slightly higher proportion of youth males in age group 20-24 years than in $15-19$ (70\% vs. 68\%) had used condom at last sex with most recent partner other than wife or non-live-in partner indicating that youth of lower ages could be more vulnerable in contracting STIs as they are comparatively not found using condom during risky sexual practices. Lower mean age at first sex 
(16.8 years) among youth, whose most recent sex partner was other than wife or non-live-in partner also suggests that youth of lower ages are more engaged in risky sexual practices.

Data analysis on condom use at last sex with most recent partner other than wife or non-live-in partner using multivariate regression analysis showsthat youth males in higher age group, i.e. in 20-24 years are 1.430times more likely to use condom at last sex with most recent partner other than wife or non-live-in partner than youthin lower age group of 15-19 years.It is also seen from the data analysis that there is 1.049 times more likely to use condom at last sex with most recent partner other than wife or non-live-in partner if there is a unit increase in age at first sex for youth males. However, the values of odds ratios arenot found statistically significant at $\mathrm{p} \leq 0.05$ level.

\section{Marital status}

There was no case of ever married youth male using condom at last sex with most recent partner other than wife or non-live-in partner. However, the number of ever married youth males enumerated in the survey was small in magnitude. Among never married youth males whose most recent sex partner was other than wife or non-live-in partner, 71 percent had used condom at last sex. Ever married youth males are 0.020 times less likely (with 95\%CI of 0.001-0.730) to use condom at last sex with most recent partner other than wife or non-live-in partner than never married youth which is statistically significant as well at $\mathrm{p}<0.05$ level.

\section{Migration and travel away from home}

More non-migrant youth males than migrants (73\% vs. 54\%) had used condom at last sex with most recent partner other than wife or non-live-in partner. Likewise, more youth males who did not travel away from home in the past 12 months had used condom at last sex with most recent partner other than wife or non-live-in partner compared to those who were away from home at least once during the same period (75\% vs. 69\%). Migrant youth males are 0.585 times less likely to use condom at last sex with most recent partner other than wife or non-live-in partner than their non-migrant counterparts, while on the other hand, youth males who did not travel away from home in the past 12 months are 1.216 time more likely to use condom at last sex with most recent partner other than wife or non-live-in partner than those who did so at least once. However, the odds ratios arenot found statistically significant at $\mathrm{p} \leq 0.05$ level.

The model $\chi^{2}$ value presented in the table is significant at $\mathrm{p} \leq .01$ and explained 8.7 to 12.3 percent of variance on condom use at last sex with most recent partner other than wife or non-live-in partner for youth males. The predicted values are also not different significantly from the observed data with insignificant value ( $p>.05)$ of Hosmer and Lemeshow's $\chi^{2}$ goodness of fit.

\section{Religion}

Most of the Hindu youth males (71\%) had used condom at last sex with most recent partner other than wife or non-live-in partner than their counterparts who follow Muslim and Bouddha religions (69\% and $47 \%$ respectively). Fifty percent each of Kirat and Christian youth males had used condom at last sex with most recent partner other than wife or non-live-in partner, but the number of cases is small in magnitude for these religious groups. Youth males of rests of all the religious 
groups are less likely to use condom at last sex with most recent partner other than wife or nonlive-in partner than their Hindu counterparts. The figures of odds ratios for followers of Christian, Kirat, Bouddha and Muslim religions are 0.196, 0.404, 0.553 and 0.672 respectively. But none of these values are found statistically significant at $\mathrm{p} \leq 0.05$ level.

\section{Caste/ethnicity}

More than 83 percent of Hill Brahmin youth males had used condom at last sex with most recent partner other than wife or non-live-in partner followed by Hill Chhetri (81\%), Terai Janajati (74\%), other Terai caste and Hill Dalit (73\% each), Muslim (69\%), Hill Janajati (61\%), Newar (44\%) and the least proportion of Terai Dalit with 39 percent. Except youth males of Hill Brahmin, rests of youth males of all the caste/ethnic groups are less likely to use condom at last sex with most recent partner other than wife or non-live-in partner than their Hill Chhetri counterparts. However, only Newar youth males are significantly correlated with condom use as they are 0.228 times less likely (with $95 \% \mathrm{CI}$ of $0.055-0.940$ and $\mathrm{p}<0.05$ ) to use condom at last sex with most recent partner other than wife or non-live-in partner than youth males of Hill Chhetri. But for other caste/ethnic groups, the values of odds ratios are not found statistically significant at $\mathrm{p} \leq 0.05$ level. While on the other hand, youth males of Hill Brahmin are more likely $(\mathrm{OR}=1.215)$ to use condom at last sex with most recent partner other than wife or non-live-in partner than their Hill Chhetri counterparts. However, the data is not statistically significant at $\mathrm{p} \leq 0.05$ level for Hill Brahmin as well.

\section{Spatial distribution}

Relatively higher proportion of youth males living in Hill area had used condom at last sex with most recent partner other than wife or non-live-in partner (71\%) compared to their counterparts living both in Mountain (68\%) and Terai (67\%). Similarly, the highest proportion of youth males living in Far-western region (88\%) had used condom at last sex with most recent partner other than wife or non-live-in partner than their counterparts living in other regions: 76 percent in Eastern, 73 percent in Mid-western, 71 percent in Western and 58 percent in Central regions. Likewise, it was also highest in Province 7 with same figure of 88 percent followed by Province 4 (78\%), Province 1 (74\%), Province 5 (70\%), Province 6 (69\%), Province 2 (66\%), and the least in Province 3 with only 54 percent.

Youth males living in Terai are 0.235 times less likely (with 95\%CI of $0.061-0.911$ ) to use condom at last sex with most recent partner other than wife or non-live-in partner than youth males living in Hill, which is also statistically significant at $\mathrm{p}<0.05$ level. Youth males of Mountain are also less likely $(\mathrm{OR}=0.635)$ to use condom at last sex with most recent partner other than wife or non-live-in partner than youth males of Hill, but the data is not statistically significant at $\mathrm{p} \leq 0.05$ level in this case.

Likewise, youth males of Far-western region are 8.262 times more likely (with 95\%CI of 1.19757.006) to use condom at last sex with most recent partner other than wife or non-live-in partner than their counterparts of Central region, which is statistically significant as well at $\mathrm{p}<0.05$ level. Whereas, youth males of Western and Mid-western regions are less likely (OR=0.900 and $\mathrm{OR}=0.939$ respectively) to use condom at last sex with most recent partner other than wife or non- 
live-in partner than youth males of Central region. However, the odds ratios are not statistically significant at $\mathrm{p} \leq 0.05$ level.

Similarly, youth males of rests of all the provinces are more likely to use condom at last sex with most recent partner other than wife or non-live-in partner than their counterparts of Province 3. The values of odds ratios for Province 5, Province 2 and Province 4 are 5.258, 4.606 and 2.100 respectively. But none of these data are statistically significant at $\mathrm{p} \leq 0.05$ level.

The model $\chi^{2}$ value presented in the table isinsignificant ( $\mathrm{p}>$.05) but the model explained 12.9 to 18.2 percent of variance on condom use at last sex with most recent partner other than wife or nonlive-in partner by two different $\mathrm{R}^{2}$ values. The predicted values of the model are not different significantly from the observed data as the value of Hosmer and Lemeshow's $\chi^{2}$ goodness of fit is found to be insignificant $(\mathrm{p}>.05)$.

\section{DISCUSSION}

Level of education has some positive effects on condom use at last sex with most recent partner other than wife or non-live-in partner. With increasing level of education, except for primary level, more youth males had used condom, but youth males having primary level of education are less likely to use condom than those having higher than secondary level of education, which is statistically significant. Most of not working youth males had used condom at last sex with most recent partner other wife or non-live-in partner compared to those involved in manual work, agriculture and non-agriculture occupations. Not working youth males are more likely to use condom than those engaged agricultural occupation with statistical significance. However, there was not much variation among youth males currently not working and working at the time of enumeration. Similarly, there is no any pattern as such in condom use at last sex with most recent partner other than wife or non-live-in partner by differential in wealth index of youth males. However, it is observed that more youth males living in rural area than in urban area had used condom at last sex with most recent partner other than wife or non-live-in partner.

As for effect of mass media, more youth males reading newspapers/magazines or listened to radio or watched television less than once a week had used condom at last sex with most recent partner other than wife or non-live-in partner than both of their counterparts who used these mass media not at all and at least once a week. This may indicate that frequency of using mass media has little effects on condom use at last sex with non-regular partner.

Relatively, a little more youth males in age group 20-24 years had used condom at last sex with most recent partner other than wife or non-live-in partner compared to those in 15-19 years indicating that more youth in lower ages practices risky sexual activities. Lower mean age at first sex (16.8 years) among youth who had most recent sex partner other than wife or non-live-in partner also suggests this incidence.

Although the number of ever married youth males enumerated in the survey who had most recent sex partner other than wife or non-live-in partner, was small in magnitude, there was none of them using condom at last sex. It is found with statistical significance that ever married youth males are less likely to use condom at last sex with most recent partner other than wife or non-live-in partner than never married youth. 
More non-migrant youth males than migrants had used condom at last sex with most recent partner other than wife or non-live-in partner. Likewise, more youth males who did not travel away from home in the past 12 months had used condom at last sex with most recent partner other than wife or non-live-in partner compared to those who were away from home at least once during the same period.

Most of the Hindu youth males had used condom at last sex with most recent partner other than wife or non-live-in partner followed by Muslim.But only less than one-half youth males of other religious group has used condom at last sex. Likewise, more Hill Brahmin youth males had used condom at last sex with most recent partner other than wife or non-live-in partner followed by Hill Chhetri, Terai Janajati, other Terai caste, Hill Dalit, Muslim, Hill Janajati, Newar and Terai Dalit. Statistical significance of data indicates that Newar youth males are less likely to use condom at last sex with most recent partner other than wife or non-live-in partner than youth males of Hill Chhetri.

Comparatively more youth males living in Hill area had used condom at last sex with most recent partner other than wife or non-live-in partner than to their counterparts living both in Mountain and Terai. Statistical significance of data shows that youth males living in Terai are less likely to use condom at last sex with most recent partner other than wife or non-live-in partner than youth males living in Hill.

Similarly, more youth males living in Far-western region had used condom at last sex with most recent partner other than wife or non-live-in partner followed by youth males of Eastern, Midwestern, Western and Central regions. Youth males of Far-western region are more likely to use condom at last sex with most recent partner other than wife or non-live-in partner than their counterparts of Central region with statistically significant. The proportion of youth males using condom at last sex with most recent partner other than wife or non-live-in partner is highest in Province 7 followed by Province 4, Province 1, Province 5, Province 6, Province 2 and the least in Province 3.

\section{CONCLUSION}

As level of education increases, there is increase in proportion of youth males using condom at last sex with most recent partner other than wife or non-live-in partner. Youth males with primary level of education are less likely to use condom than those who have higher than secondary level of education. Not working youth males are more likely to use condom than those engaged agricultural occupation. There is not found significant effect of wealth status, place of residence and frequency of exposure to different mass media in condom use by youth males at last sex with most recent partner other than wife or non-live-in partner.

Ever married youth males are less likely to use condom at last sex with most recent partner other than wife or non-live-in partner than their never married counterparts. Despite lower mean age at first sex among youth who had most recent sex partner other than wife or non-live-in partner, there is no significant effect of ages on use of condom. Likewise the effects of migration status of youth males and their travelling away from home at least once in the past 12 months in using condom at last sex with most recent partner other than wife or non-live-in partner are not found significant. 
Religion has no significant effect on condom use at last sex with most recent partner other than wife or non-live-in partner. There is significant effect that Newar youth males are less likely to use condom at last sex with most recent partner other than wife or non-live-in partner than youth males of Hill Chhetri. But other caste/ethnic groups are not significantly correlated with condom use at last sex.

Youth males living in Terai are less likely to use condom at last sex with most recent partner other than wife or non-live-in partner than youth males living in Hill. Similarly, youth males living in Far-western region are more likely to use condom at last sex with most recent partner other than wife or non-live-in partner compared to their counterparts of Central regions. But provincial differential has no significant effect on condom use at last sex.

\section{Limitation of the study}

This study is limited to the issue of condom used at last sex with most recent partner other than wife or non-live-in partner by Nepalese youth males (15-24 years). The effects of some selected socio-economic variables like level of education, occupation, current working status, wealth index, place of residence and frequency of exposure to mass media like newspapers/magazines, radio and television; demographic variables like age group, age at first sex, marital status, migration status and travelling away from home in the past 12 months; and cultural variables like religion and caste/ethnicity, and spatial distribution by ecological zones, development regions and provinces are determined on condom use at last sex with most recent partner other than wife or non-live-in partner using multivariate logistic regression analysis.

\section{Acknowledgements}

I would like to appreciate the support of ICF and Bridgette Wellington, Data Archivist, The Demographic and Health Survey (DHS) Program for proving data sets of 2016 Nepal Demographic and Health Survey.

\section{REFERENCES}

Adair, T. (2008). Men's condom use in higher-risk sex: Trends and determinants in five SubSaharan countries. DHS working papers. Washington D.C.: USAID.

Amornkul, P.N., Vandenhoudt, H., Nasokho, P., Odhiambo, F., Mwaengo, D., Hightower, A., Buvé, A., Misore, A., Vulule, J., Vitek, C., Glynn, J., Greenberg, A., Slutsker, L., \& De Cock, K.M. (2009). HIV prevalence and associated risk factors among individuals aged 13-34 years in rural western Kenya, PLoS ONE, 4(7), e6470.

Anderson, J.E., Wilson, R., Doll, L., Jones, T.S., \& Barker, P. (1999). Condom use and HIV risk behaviours among U.S. adults: Data from a national survey, Family Planning Perspectives, 31(1), 24-28.

Child Trends. (2010). Condom use. Retrieved fromhttp://childtrendsdatabank.org/?q= node/132, accessed on 31 January 2012. 
Exavery, A., Lutambi, A.M., Mubyazi, G.M., Kweka, K., Mbaruku, G., \& Masanja, H. (2011). Multiple sexual partners and condom use among 10-19 year-olds in four districts in Tanzania: What do we learn? BMC Public Health, 11, 490. Retrieved from http:// www.biomedcentral.com/1471-2458/11/490, accessed on 17 January 2012.

Ministry of Health (MoH) [Nepal], New ERA,\& ICF. (2017). Data files of Nepal demographic and health survey 2016. Kathmandu: $\mathrm{MoH}$.

Nnedu, O.N., McCorvey, S., Campbell-Forrester, S., Chang, J., Salihu, H.M., \& Jolly, P.E. (2008). Factors influencing condom use among sexually transmitted infection clinic patients in Montego Bay, Jamaica. The Open Reproductive Science Journal, 1,45-50.

Shakya, D.V. (2018). Trends in sexual practices of Nepalese youth over time 2006-2016. Tribhuvan University Journal, 32(1), 185-196.

United Nations Children's Fund (UNICEF). (2007). The state of the world's children 2008. New York: UNICEF.

Waithaka, M., \& Bessinger, R. (2001). Sexual behaviour and condom use in the context of HIV prevention in Kenya. Nairobi, Kenya: Population Services International. 